\title{
FACILITY FOR INVESTIGATING THE VIBRATION OF THE PLATE WITH MAGNETORHEOLOGICAL FLUID
}

\begin{abstract}
SUMMARY
This study briefly outlines the structure of the test facility for investigating the behaviour of a sandwich plate filled with magnetorheological (MR) fluid. The plate has two outer layers made of aluminium and the space between them is filled with MR fluid. The test facility is engineered within the framework of the research project focused on vibration reduction in beams and plates using MR fluids. The paper outlines the design of the test facility and the measurement equipment. Measurement data are summarised, including the free and forced vibration of the plate.
\end{abstract}

Keywords: MR fluid, plate vibration, damping coefficient

\section{STANOWISKO DO BADANIA DRGAŃ PEYTY Z CIECZA MAGNETOREOLOGICZNA}

$W$ artykule przedstawiono stanowisko laboratoryjne do badania ptyt z cieczq magnetoreologiczna (MR). Badana plyta jest plyta trójwarstwowa, $w$ której dwie zewnętrzne warstwy sq wykonane z aluminium, a przestrzeń między nimi jest wypetniona ciecza MR. Stanowisko zbudowano w ramach projektu badawczego dotyczqcego redukcji drgań belek i plyt przy wykorzystaniu cieczy MR. W pracy przedstawiono strukture stanowiska oraz oprzyrzqdowanie uktadu pomiarowego. Zamieszczono wyniki pomiarów drgań własnych i wymuszonych plyty.

Stowa kluczowe: ciecz MR, drgania płyt, wspótczynnik tlumienia

\section{INTRODUCTION}

Many structural elements are characterised by continuous distribution of mass and rigidity. Suppressing the vibration of these elements is particularly difficult. In recent years, thanks to new developments in the field smart materials and control strategies, the research work has focused on optimal applications of those new materials. Smart materials include magnetorheological fluids, whose mechanical parameters are associated with the applied magnetic field. Under the action of magnetic field, the rigidity and damping of the fluid layer are changed (Yeh and Chen 2005). Since these changes occur within very short periods (of the order of milliseconds), MR fluids are suitable for applications in highly dynamic systems. Smart materials, such as electroand magnetorheological fluids, are particularly useful in supressing vibrations of beams, plates and shell structures (Rajamohan et al. 2010; Sapiński and Snamina 2008; Snamina et al. 2008; Yeh and Chen 2005).

The authors of (Rajamohan et al. 2010; Sapiński and Snamina 2008)investigated the dynamic response of an MR sandwich plate. They considered a fully treated plate structure with an MR fluid layer along the entire plate length. Alternatively, MR fluid can be applied only over a critical plate's section to achieve more effective vibration damping. While sandwich plate structures are studied extensively, there are fewer reports on applications of controllable fluids such as magnetorheological and electrorheological fluids in sandwich plates (Yeh and Chen 2005).

Testing is done on a three-layer sandwich plate consisting of two aluminium layers and a MR fluid layer in between. The purpose of the testing is to explore the potential applications of a MR fluid layer to reduction of the plate's transverse vibration through the action of controlled magnetic field. The testing covers the free and damped vibration of a plate fabricated specially for the purpose of the research program measured at the test facility.

\section{PLATE STRUCTURE}

The cross-section of the sandwich plate is shown in Figure 1. Its outer layers are made of aluminium (AP 11) with MR fluid in between (140 CG Lord Corporation). The outer layers $450 \times 550 \mathrm{~mm}$ are made of the aluminium sheet $1 \mathrm{~mm}$ in thickness. On the edges, fixed in clamps, the outer layers are separated with adhesive spacers $2 \times 5 \mathrm{~mm}$, made of the same aluminium sheet. The plate's free edges, those not fixed in clamps, are sealed with silicone rubber with the hardness of $50 \mathrm{ShA}$. The sealing dimensions are $2 \times 5 \mathrm{~mm}$. The prepared sandwich plate is filled with MR fluid.

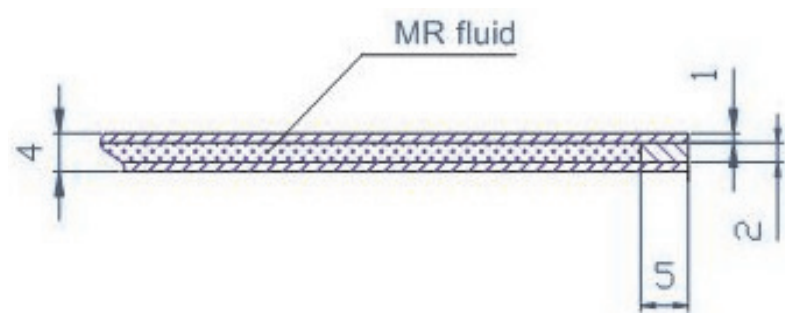

Fig. 1. Cross-section of the sandwich plate

\footnotetext{
* AGH University of Science and Technology, Faculty of Mechanical Engineering and Robotics, Department of Process Control, Krakow, Poland
} 


\section{DESCRIPTION OF THE TEST FACILITY}

Testing is done in the test facility shown schematically in Figure 2. The free and forced vibrations of the plate are investigated, by measuring the displacement of the plate's free corner. Measurements are taken when the position of the electromagnet and current supplying the electromagnet are varied. Depending on the adopted boundary conditions, special clamps are used to fix one, two or four edges of the plate, connecting them to the shaker core TIRA S514. The clamp construction is adjusted to the requirements imposed by the given boundary conditions. The shaker is controlled via the module LMS SCADAS III, supported by the computer with dedicated software TestLab. The shaker control uses a piezoelectric acceleration meter manufactured by PCB Piezoelectronics M345C03. The steering signal to the shaker is ampli- fied by the amplifier TIRA BAA500. The displacement of the plate's free corner is measured with a laser sensor SENSOPART FT50RLA. The measurement system is used incorporating a portable computer and a dedicated card National Instruments. Data acquisition is effected using the card and the dedicated software DasyLab. The facility for testing sandwich plates is shown in Figure 3.

The load-bearing structure in the test facility is a metal frame made of aluminium profiles. A system of guides is attached to the frame allowing the control of the electromagnet's position with respect to the plate. The plate's edges are fixed in specially designed clamps, to account for the assumed boundary conditions. The clamp holds the plate and connects it to the shaker. A laser displacement sensor is attached to the frame and its position can be varied with respect to the plate.

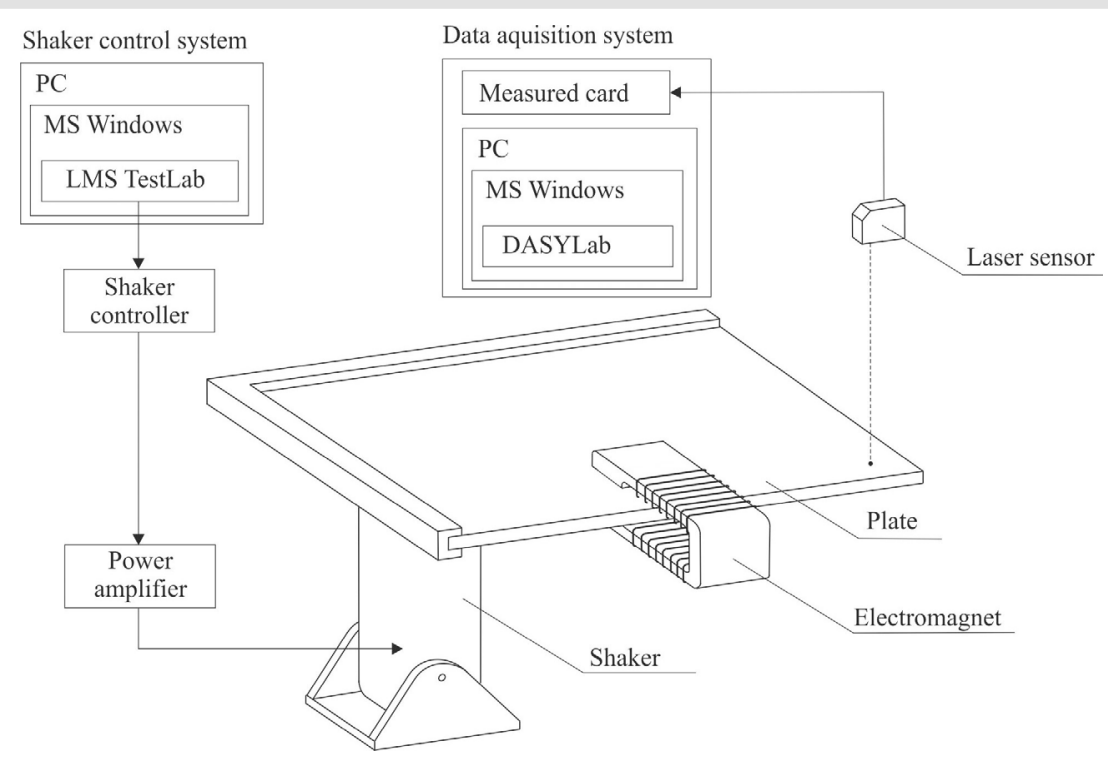

Fig. 2. Schematic diagram of the test facility

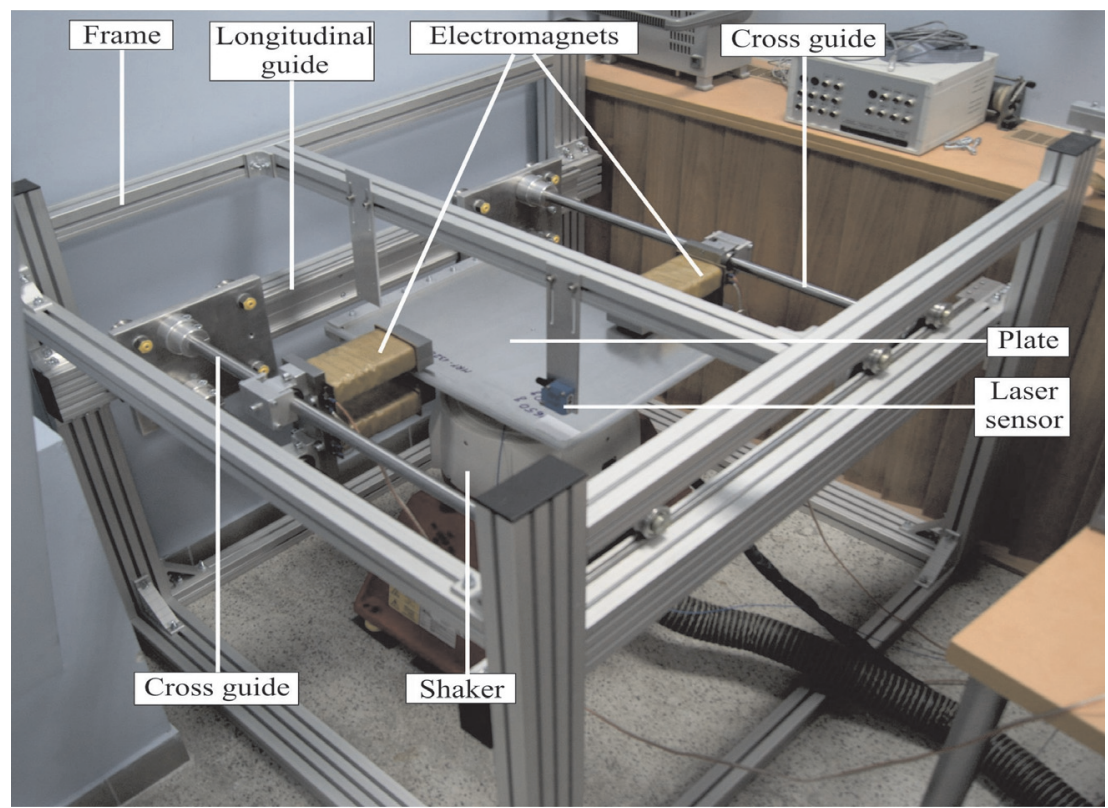

Fig. 3. Facility for testing sandwich plate - general view 


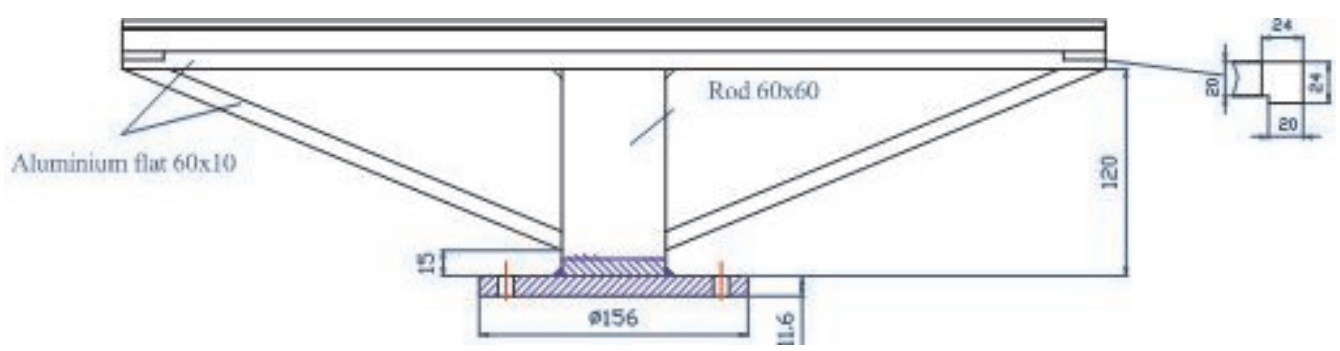

Fig. 4. The system of clamps fixed the plate edges to the shaker

According to the assumed boundary conditions, the plate's edges are secured in one of the designed clamps. The clamps (Fig. 4) are made of aluminium alloy PA 38 using the welding techniques.

\section{MEASUREMENT RESULTS}

Measurements are taken of free and forced vibrations of plate. Its two edges are fixed in clamps. Free vibrations are induced by moving the free corner of the plate from the position of static equilibrium. Forced vibrations are induced using an electromagnetic shaker and displacements of a plate's free corner are registered. In the course of the measurement procedure, the electromagnet's position with respect to the plate and the current supplying the electromagnet are varied.

Selected results of measurements of free vibrations are shown in Figures 5 and 6. They are registered during the measurements taken while the magnetic field is absent (Fig. 5) and under the action of a magnetic field generated by an electromagnet supplied with current 2 A (Fig. 6). If higher current were applied whilst the spacing between the electromagnet poles remained the same, the plate would be attracted to one of the poles and would not vibrate at all.

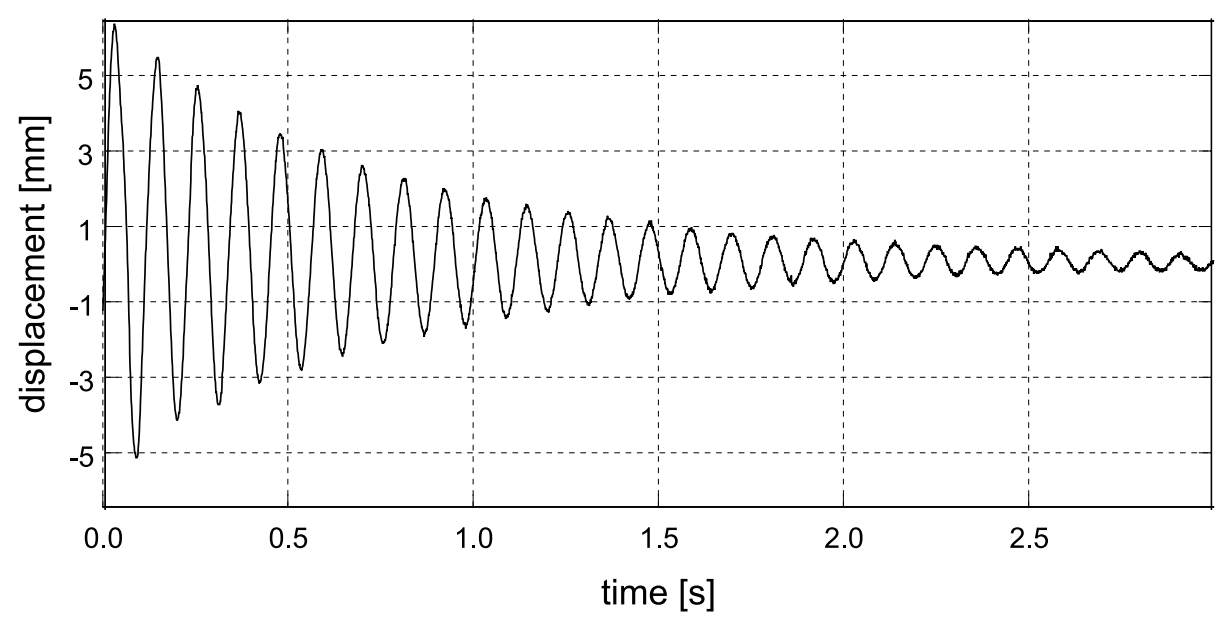

Fig. 5. Free vibrations of a plate's free corner (current $I=0 \mathrm{~A}$ )

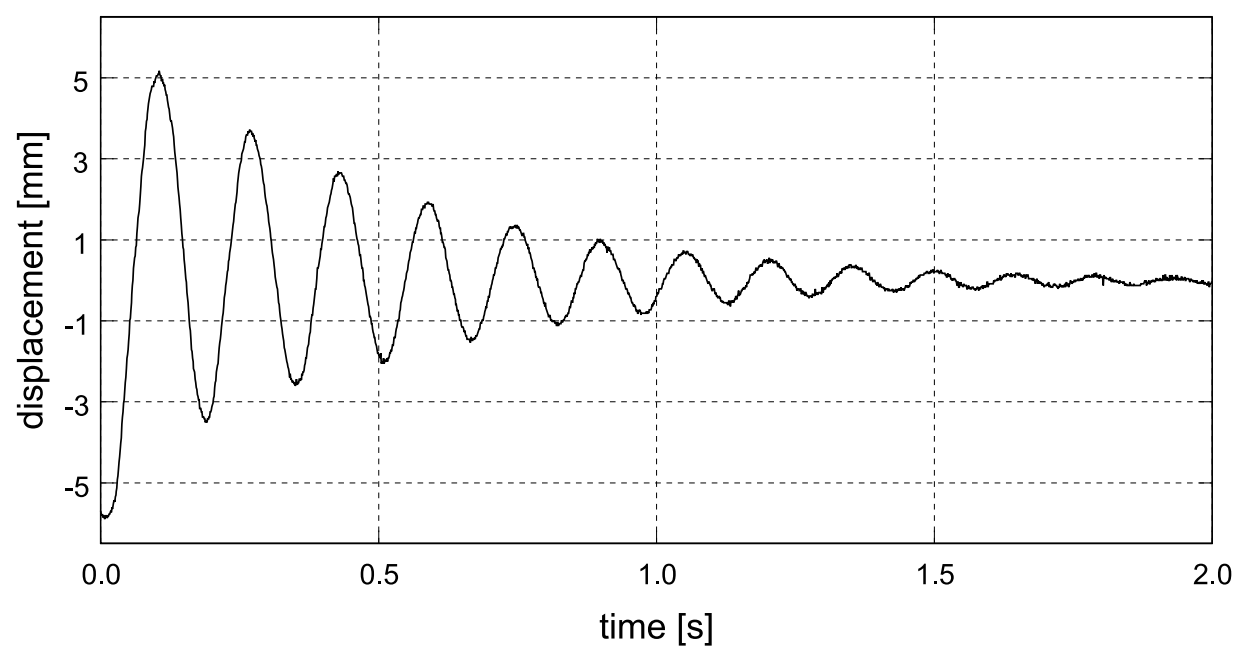

Fig. 6. Free vibrations of a plate's free corner (current $I=2 \mathrm{~A}$ ) 
Vibration damping is much more effective under the action of a magnetic field than when the MR fluid inside the sandwich plate is not activated by magnetic fields. As expected, the increased current leads to enhanced damping. Variations of the period of free vibration appear to follow the same pattern. Under the action of a magnetic field, the period of free vibration is larger. Therefore, the action of MR fluids activated by magnetic fields leads to variation of both the plate's damping and stiffness.

Selected forced vibrations data are shown in Figures 7 and 8. Results are obtained under the applied kinematic excitations. Displacements of the plate's edges fixed to the shaker are sine displacements of constant amplitude and slow-growing frequency. The frequency interval is chosen such that it should coincide with the neighbourhood of the first natural frequency of the plate. By analogy to free vibration measurements, the procedure consists in varying the current supplying the electromagnet. Displacements of the plate's free corner are shown in Figure 7 (the electromagnet being off) and Figure 8 (the electromagnet being supplied with the current $I=2 \mathrm{~A}$ ).

When the magnetic field is generated (it covers a plate section only) the vibration amplitude is decidedly smaller. When the electromagnet is supplied with controlled current, variations of amplitude and frequency become less sensitive to slightly non-uniform operation of the shaker system.
Graphed plots represent the vibrations registered in frequency intervals, associated with natural frequency of plate.

\section{PRELIMINARY ANALYSIS OF RESULTS}

Registered data provide the backgrounds for calculating the basic parameters of the first mode vibrations of the plate: frequency and a dimensionless damping coefficient. Besides, it is estimated how viscous damping and Coulomb friction contribute to decrease of plate vibration. The actual proportions between the viscous damping and Coulomb friction can be analysed taking into account different geometries of the damped vibration enveloped in the two cases. Taking into account the proportions between the two types of damping, the formula expressing the amplitude decrease in the function of time can be written in the form:

$$
A(t)=A_{0}\left[\beta e^{-\alpha\left(t-t_{0}\right)}+(1-\beta)\left(1-\frac{t-t_{0}}{T_{c}}\right)\right]
$$

where $\beta$ describes the contribution of the viscous damping whereas 1- $\beta$ describes the contribution of the Coulomb friction in whole vibration damping. Parameters $\alpha$ and $T_{\mathrm{c}}$ are associated with the level of decrease of amplitude due to viscous damping and Coulomb friction. The parameters $\beta$, $\alpha$ and $T_{\mathrm{c}}$ can be calculated using results of experiments.

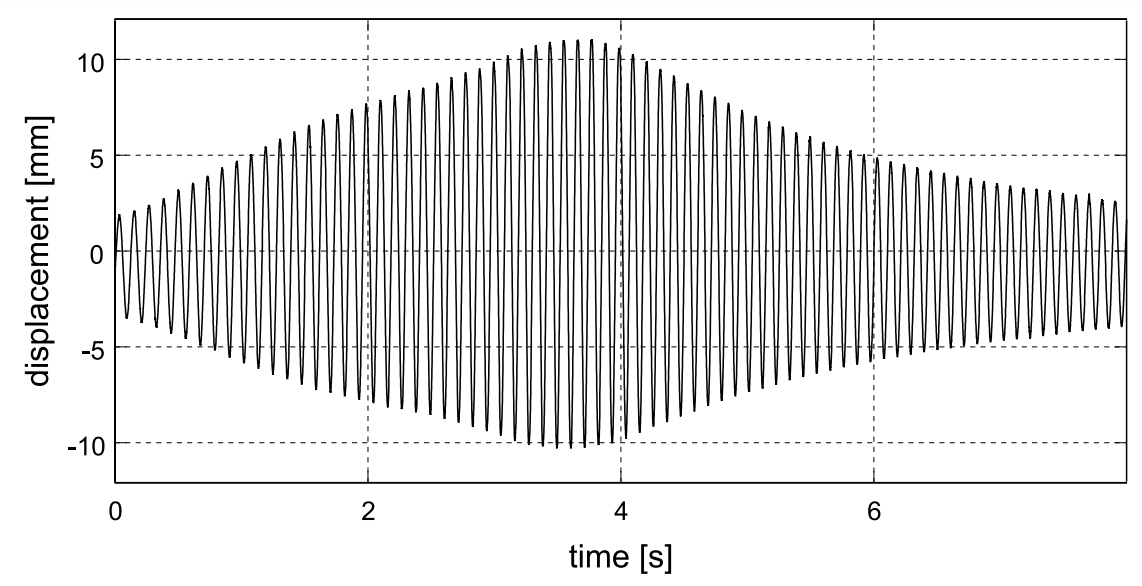

Fig. 7. Forced vibration of a plate's free corner (current $I=0$ A)

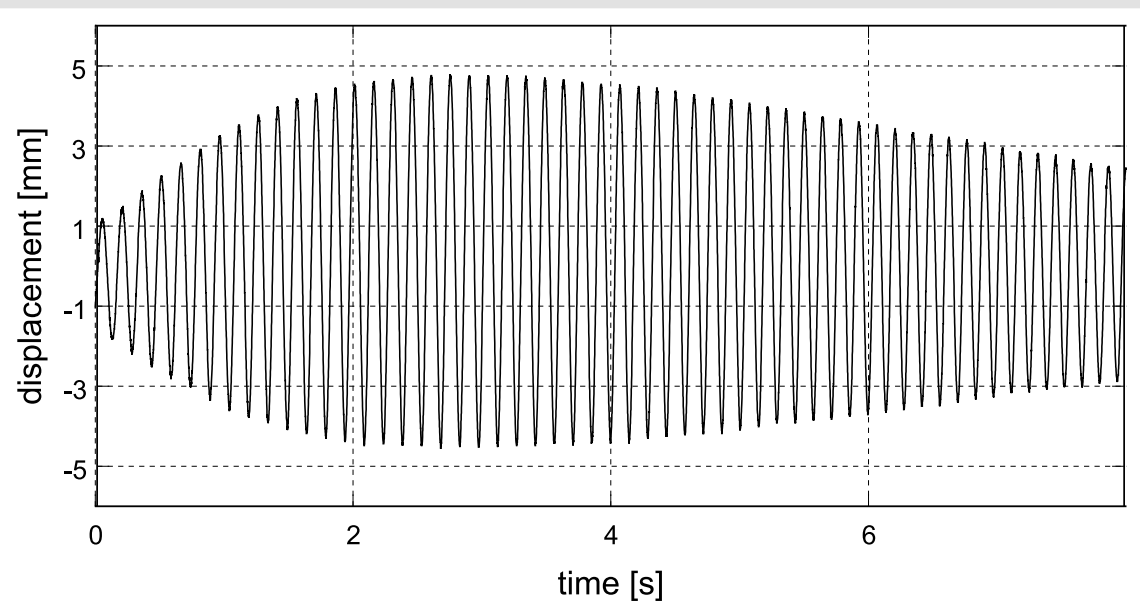

Fig. 8. Forced vibration of a plate's free corner (current $I=2 \mathrm{~A}$ ) 
Using the minimum mean square error method the unknown parameters are estimated. The value of parameter $\beta$ is equal to 0.96 in the case when the current was equal to $I=2 \mathrm{~A}$. The registered displacements seem to confirm the expectation that the damping is not purely viscous but the contribution of Coulomb friction is small.

\section{CONCLUSIONS}

The test facility has been designed specially for the purpose of the experiment involving the measurements of free and forced vibrations of a three-layer sandwich plate filled with MR fluid. The design of the test facility enables the electromagnet to be moved with respect the plate in such a manner that the magnetic field should be applied to the selected plate's sections. The facility incorporates the shaker and a measurement and data recording circuit.

Functional tests have been performed as well as measurements of free and forced vibrations of the plate under the action of a magnetic field and when no magnetic field was applied. As anticipated, the internal damping of the plate tends to increase when the MR fluid layer is affected by the magnetic field. Free vibrations tend to be reduced more effectively and amplitudes of forced vibrations in the neighbourhood of the resonance frequency tend to be smaller. The analysis of the damping process reveals its complex nature, involving viscous and dry friction.

This study is financed through the research program no N501 223337.

\section{References}

Rajamohan V., Rakheja S., Sedaghati R., 2010, Vibration analysis of a partially treated multilayer plate with magnetorheological fluid, Journal of Sound and Vibration, 392, pp. 3451-3469.

Sapiński B., Snamina J., 2008, Modeling of an adaptive beam with $M R$ fluid, Solid State Phenomena, vols. 147-149, pp. 831-838.

Snamina J., Sapiński B., Romaszko M., 2010, Modelowanie belki z cieczq magnetoreologicznq metodq elementów skończonych, Modelowanie Inżynierskie 8, Gliwice.

Yalcinitas M., Dai H., 2004, Vibration suppression capabilities of magneto-rheological materials based adaptive structures, Smart Materials and Structures, 13, pp. 1-11.

Yeh J.Y., Chen L.W., 2005, Dynamic stability of a sandwich plate with a constraining layer and electrorheological fluid core, Journal of Sound and Vibration, 285, pp. 637-652. 